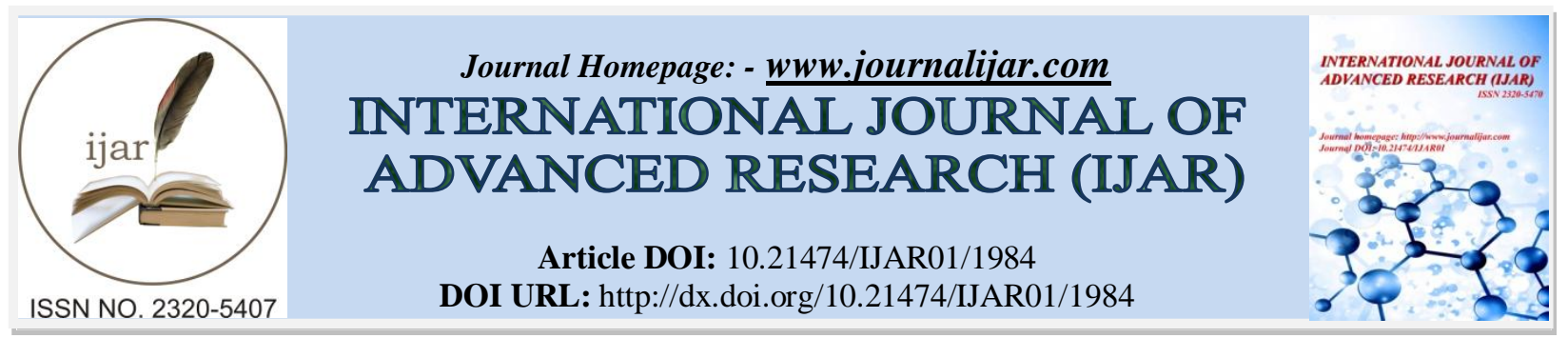

RESEARCH ARTICLE

\title{
IMMUNO-HISTOCHEMICAL EXPRESSION OF MCL-1 IN TESTICULAR BIOPSY OF PATIENTS WITH AZOOSPERMIA.
}

Ula Al-Kawaz1, Sally Alaa, Ban Jumaa Qassim ${ }^{2}$ and Mohammad O. Selman ${ }^{1}$.

1. Assistant professor, University of Al-Nahrain, College of Medicine, Department of pathology and Forensic Medicine, Baghdad, Iraq.

2. Assistant professor, University of Al-Nahrain, Dean of High Institute for Infertility Diagnosis and Assisted Reproductive Technologies Baghdad, Iraq.

\section{Manuscript Info}

[.........................

Manuscript History

Received: 12 September 2016

Final Accepted: 22 October 2016

Published: October 2016

Key words:-

Azoospermia, MCL-1,

Immunohistochemical

\section{Abstract}

Background:- Azoospermia is the medical condition of a man not having any sperm in his semen.Myeloid cell leukemia-1 (Mcl-1) is a member of the Bcl2 family of proteins involved in regulation of apoptosis. It is an inhibitor of programmed cell death.

Objective:- Assess the immunohistochemical expression of MCL-1 in testicular biopsies in azoospermic patients and to correlate this expression with risk factors age, fertilization rate, quality of embryo and histopathological changes.

Patients and methods:- This cohort study included 60 patients with azoospermia, 15 male with obstructive type and 45 males with nonobstructive type.Those patients were randomly selected form the population of infertile couples who regularly visits the High Institute for Infertility Diagnosis and ART and from Kamal Al-Samarai Hospital center of fertility.

Result:- Mean histological H\&E score was significantly higher in the obstructive group, $8.67 \quad \pm 0.75$ versus $4.82 \quad \pm 2.60 \quad(\mathrm{P}<0.01)$. Additionally, mean MCL1 immunohistochemical score was significantly higher in the obstructive group than non-obstructive group, $2.73 \pm 0.46$ versus $0.84 \pm 0.95(\mathrm{P}<0.001)$. Histological $\mathrm{H}$ and $\mathrm{E}$ score was highly significantly correlated with the immunohistochemical MCL1 score $(r=0.863, \mathrm{P}<0.001)$. MCL1 score showed no significant correlation with the risk factors whereas it showed significant negative correlations with FSH, LH and prolactin and significant positive correlation with serum testosterone. Sperm isolation rate was significantly determined by higher histological and MCL 1 scores.

Conclusion:- Histological H\&E score and MCl-1 immunohistochemical score were significantly higher in the obstructive group than non-obstructive one, reflecting that apoptosis is higher in non-obstructive azoospermia and may have a role in its pathogenesis.

Copy Right, IJAR, 2016,. All rights reserved.

Corresponding Author:- Ula Al-Kawaz1. 


\section{Introduction:-}

Azoospermia is defined as the lack of sperm in male ejaculate and is suggested to be present in about $1 \%$ of all males and to account for $10-15 \%$ of the causes of infertility in men ${ }^{(\mathbf{1})}$. It is classified into two major forms: either obstructive or non-obstructive. The presence of organic obstruction in the reproductive male pathways distal to the testes is the pathognomonic pathophysiology in obstructive type ${ }^{(2)}$. Non-obstructive azoospermia (NOA) is oftenregarded as a non-medically manageable reason of infertility in men. These patients, who make up to $10 \%$ of global infertile male subjects, have abnormal spermatogenesis as with consequent azoospermia. The establishment of in vitro fertilization using intracytoplasmic sperm injection (ICSI) as a mainstay treatment modality made a number of these male patientsto be successful biologic fathers a child via surgically retrieved sperm from the testis. The obstacle, however, is to facilitate their spermatogenicactivity to enable the acquisition of sperm in their ejaculate or to improve the opportunity of a successful sperm retrieval from the testis for ICSI ${ }^{(3)}$. An accurate diagnosis of azoospermia and thorough evaluation of the patient to diagnose the cause of infertility are needed to guide appropriate treatment options and to identify the associated cost advantages, risks and hope for treatment success. The development of intracytoplasmic sperm injection (ICSI) as an effective therapy for profound male factor infertility has become a definite treatment for the majority of male reproductive tract abnormalities ${ }^{(\mathbf{1})}$.During spermatogenesis, there is a need of germ cell removal by apoptosis in order to maintain healthy germ cell development and to reach a normal sperm outcome. In cases of improper spermatogenesis with azoospermia, apoptosis of testicular sperm has also been a target of debate in the published literature ${ }^{(4)}$. The anti-apoptotic myeloid cell leukemia factor 1 (Mcl-1)was discovered based on its increased expression during cell commitment toward differentiation in a human myeloid leukemia cell line. The rapid induction and destruction of Mcl-1L has been proposed as a molecular mechanism for cells to switch between survival and apoptotic pathways in response to various stresses ${ }^{(5)}$. So the aim of the present study was to evaluate the immunohistochemical expression of MCL-1 in histological sections from patients with obstructive and non-obstructive azoospermia.

\section{Patients and Methods:-}

This prospective cohort study included 60 patients with azoospermia, 15 male with obstructive type and 45 males with non-obstructive type. Those patients were randomly selected form the population of infertile couples who regularly visits the High Institute for Infertility Diagnosis and Assisted Reproductive Technologies and from Kamal Al-Samarai Hospital center of fertility and IVF (Baghdad / Iraq). Testicular biopsies of azoospermic patients were obtained and fixed with modified Zenker (fixative) and then processed routinely to produce paraffin blocks. From each paraffin block, 2sections of $5 \mu \mathrm{m}$ thickness were taken: one section was stained with $\mathrm{H} \& \mathrm{E}$ to study histopathological changes and the other was stained immunohistochemically for MCL-1 monoclonal antibody. All male patients were subjected to hormonal assays including: FSH, LH, testosterone and prolactin, whereas female partners were subjected to assessment of FSH, LH, progesterone and estradiol.

Statistical analysis was performed using SPSS version 22. Data were presented as number and percentage for categorical variables or as mean $\pm \mathrm{SD}$ for numerical variables. For the analysis of numeric variables, independent student test was used in case of normal distribution and Mann Whitney U test in case of non-normal distribution. Chi-square test and Fischer Exact tests were used to study association between any two categorical variables. Correlation and regression analysis was used between immunohistochemical and histological scoring variables. The level of significance was considered at 0.05 .

\section{Results:-}

General characteristics of the Azoospermic men and their female partners are shown in tables 1 and 2.

Table 1:- General characteristic of the study sample.

\begin{tabular}{|l|c|c|c|c|}
\hline \multicolumn{1}{|c|}{ Characteristic } & $\begin{array}{c}\text { Obstructive } \\
(\mathbf{N}=\mathbf{1 5})\end{array}$ & $\begin{array}{c}\text { Non-Obstructive } \\
(\mathbf{N}=\mathbf{4 5})\end{array}$ & $\begin{array}{c}\text { Total } \\
(\mathbf{N}=\mathbf{6 0})\end{array}$ & $\begin{array}{l}\text { P* } \\
\text { Age (mean }+ \text { SD) years }\end{array}$ \\
\hline Smoker N (\%) & $4.07 \pm 6.82$ & $33.07 \pm 7.84$ & $33.32 \pm 7.55$ & $0.661 \dagger$ \\
\hline Varicocele N (\%) & $3(26.7)$ & $15(33.3)$ & $19(31.7)$ & $0.755^{*}$ \\
\hline RGUTI N (\%) & $3(20.0)$ & $8(17.8)$ & $11(18.3)$ & $1.000^{*}$ \\
\hline Chemical Toxin N (\%) & $2(13.3)$ & $1(2.2)$ & $4(6.7)$ & $0.073^{*}$ \\
\hline Physical Toxin N (\%) & $3(20.00)$ & $7(15.6)$ & $9(15.0)$ & $1.000^{*}$ \\
\hline Congenital anomaly N (\%) & $1(6.7)$ & $10(22.2)$ & $13(21.7)$ & $1.000^{*}$ \\
\hline
\end{tabular}

$\dagger$ Independent samples t-test *Corrected Chi-square test; RGUTI: recurrent genitourinary tract infections 
Table 2:- General characteristics of female partners.

\begin{tabular}{|c|c|c|c|c|}
\hline Characteristic & Group 1 & Group 2 & Total & $\mathbf{P}$ \\
\hline Age (mean $\pm \mathrm{SD})$ years & $29.00 \pm 4.61$ & $27.60 \pm 6.12$ & $28.30 \pm 5.37$ & $0.485^{*}$ \\
\hline $\begin{array}{l}\text { Infertility type } \\
\text { (Primary/Secondary) }\end{array}$ & $12 / 3$ & $15 / 0$ & $27 / 3$ & $0.244 \dagger$ \\
\hline Duration (mean $\pm \mathrm{SD}$ ) years & $7.20 \pm 2.78$ & $5.60 \pm 4.27$ & $6.40 \pm 3.64$ & $0.234 *$ \\
\hline Weight (mean \pm SD) kg & $68.07 \pm 8.72$ & $66.73 \pm 9.51$ & $67.40 \pm 8.99$ & $0.692 *$ \\
\hline FSH (mean \pm SD) IU $/ \mathrm{ml}$ & $7.04 \pm 1.76$ & $7.19 \pm 1.08$ & $7.11 \pm 1.43$ & $0.785^{*}$ \\
\hline LH (mean $\pm \mathrm{SD}) \mathrm{IU} / \mathrm{ml}$ & $5.51 \pm 1.46$ & $5.93 \pm 1.09$ & $5.72 \pm 1.29$ & $0.381 *$ \\
\hline Progesterone (mean $\pm \mathrm{SD}$ ) IU $/ \mathrm{ml}$ & $15.89 \pm 3.81$ & $15.73 \pm 3.71$ & $15.81 \pm 3.70$ & $0.912 *$ \\
\hline Estradiol (mean $\pm \mathrm{SD}) \mathrm{IU} / \mathrm{ml}$ & $157.93 \pm 59.05$ & $115.00 \pm 44.71$ & $136.47 \pm 55.90$ & $0.042 * *$ \\
\hline
\end{tabular}

Group 1: Female partners of males with obstructive azoospermia; Group 2: Female partners of males with nonobstructive azoospermia; *Independent sample t-test; $\uparrow$ Fischer Exact test; ** Mann Whitney U test

Mean serum hormonal levels with corresponding ranges were presented in table 3 and figure 1. Comparisons revealed the following: serum FSH, LH and prolactin were significantly higher in the non-obstructive group whereas serum testosterone was significantly lower in the non-obstructive group.

Table 3:- Comparison of mean serum hormonal levels between obstructive and non-obstructive azoospermia patients.

\begin{tabular}{|c|c|c|c|c|}
\hline Hormone & Group & Mean \pm SD & Range & $\mathbf{P}$ \\
\hline \multirow[t]{3}{*}{ FSH } & Obstructive & $5.96 \pm 1.06$ & $4.5-8.1$ & \multirow[t]{3}{*}{$0.001 *$} \\
\hline & Non-Obstructive & $12.81 \pm 8.37$ & $2.4-38.6$ & \\
\hline & Total & $11.10 \pm 7.84$ & $2.4-38.6$ & \\
\hline \multirow[t]{3}{*}{$\mathrm{LH}$} & Obstructive & $5.29 \pm 1.18$ & $3.2-7.2$ & \multirow[t]{3}{*}{$0.017 *$} \\
\hline & Non-Obstructive & $7.58 \pm 3.63$ & $1.6-18$ & \\
\hline & Total & $7.01 \pm 3.34$ & $1.6-18$ & \\
\hline \multirow[t]{3}{*}{ Prolactin } & Obstructive & $7.75 \pm 3.62$ & $4.7-20$ & \multirow[t]{3}{*}{$<0.001 \dagger$} \\
\hline & Non-Obstructive & $12.56 \pm 3.76$ & $0.55-21.4$ & \\
\hline & Total & $11.36 \pm 4.25$ & $0.55-21.4$ & \\
\hline \multirow[t]{3}{*}{ Testosterone } & Obstructive & $22.20 \pm 1.39$ & $20.1-24.6$ & \multirow[t]{3}{*}{$<0.001^{*}$} \\
\hline & Non-Obstructive & $3.09 \pm 2.58$ & $0.86-15.5$ & \\
\hline & Total & $7.87 \pm 8.67$ & $0.86-24.6$ & \\
\hline
\end{tabular}

*Mann Whitney U test; †Independent samples t-test

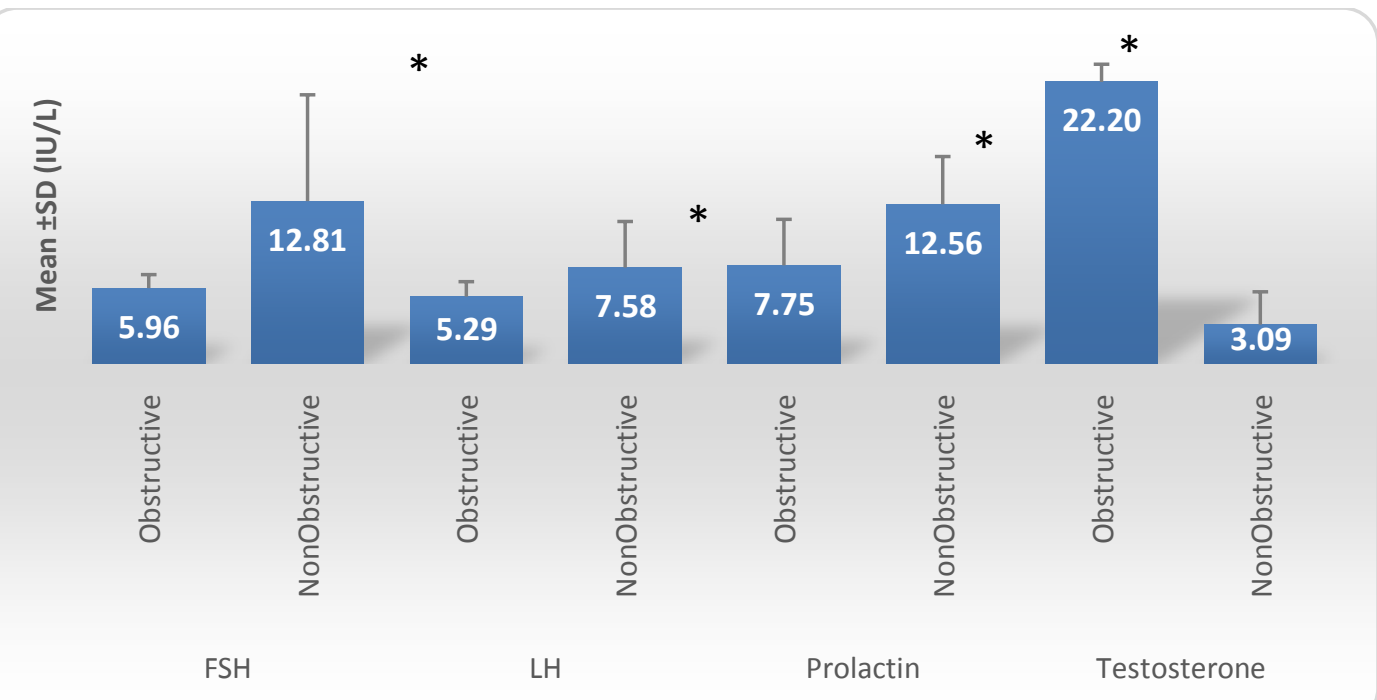

Figure 1:- Bar chart showing comparison of mean serum hormonal levels between obstructive and obstructive azoospermia groups. 
Mean histological $\mathrm{H}$ and $\mathrm{E}$ score was significantly higher in the obstructive group, $8.67 \pm 0.75$ versus $4.82 \pm 2.60$ $(\mathrm{P}<0.01)$. Additionally, mean MCL1 immunohistochemical score was significantly higher in the obstructive group than non-obstructive group, $2.73 \pm 0.46$ versus $0.84 \pm 0.95(\mathrm{P}<0.001)$, as shown in table 4 and figure 2 .

Table 4:- Comparison of H\&EScore and MCL1Score scores between obstructive and obstructive azoospermia groups.

\begin{tabular}{|c|c|c|c|c|}
\hline Score & Group & Mean \pm SD & Range & P* \\
\hline \multirow{3}{*}{ H\&E Score } & Obstructive & $8.67 \pm 0.75$ & $7.5-10.0$ & $<0.001$ \\
\cline { 2 - 4 } & Non-Obstructive & $4.82 \pm 2.60$ & $1.0-9.0$ & \\
\cline { 2 - 4 } & Total & $5.78 \pm 2.83$ & $1.0-10.0$ & \\
\hline \multirow{3}{*}{ MCL1Score } & Obstructive & $2.73 \pm 0.46$ & $2.0-3.0$ & $<0.001$ \\
& Non-Obstructive & $0.84 \pm 0.95$ & $0.0-3.0$ & \\
\cline { 2 - 4 } & Total & $1.32 \pm 1.19$ & $0.0-3.0$ & \\
\cline { 2 - 4 } & \multicolumn{2}{|c}{} &
\end{tabular}

*Mann Whitney U test

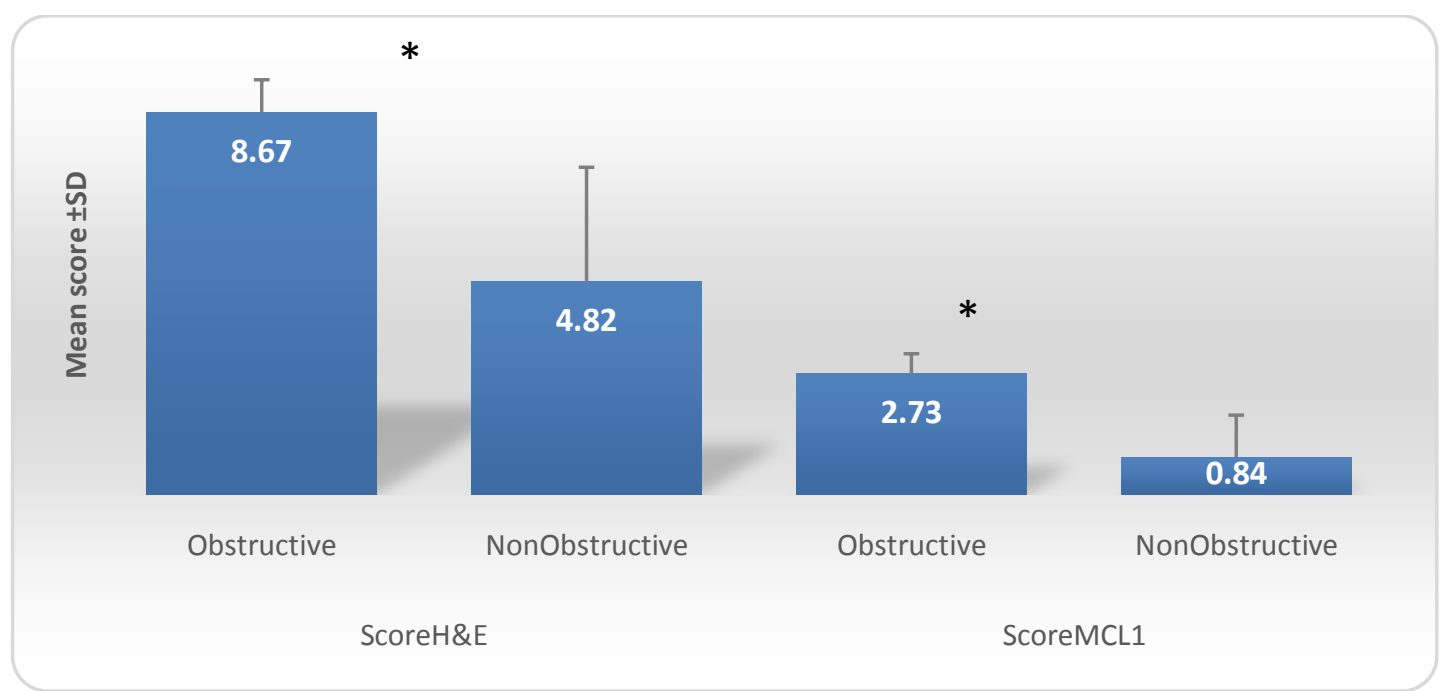

Figure 2:- Bar chart showing comparison of H\&EScore and MCL1Score scores between obstructive and nonobstructive azoospermia groups.

Histological $\mathrm{H}$ and $\mathrm{E}$ score was highly significantly correlated with the immunohistochemical MCL1 score $(\mathrm{r}=$ $0.863, \mathrm{P}<0.001$ ), and regression analysis showed that adjusted $\mathrm{R}^{2}$ was 0.891 which means that the regression model can explain perfectly $89.1 \%$ of the correlation between the two parameters, figure 3 .

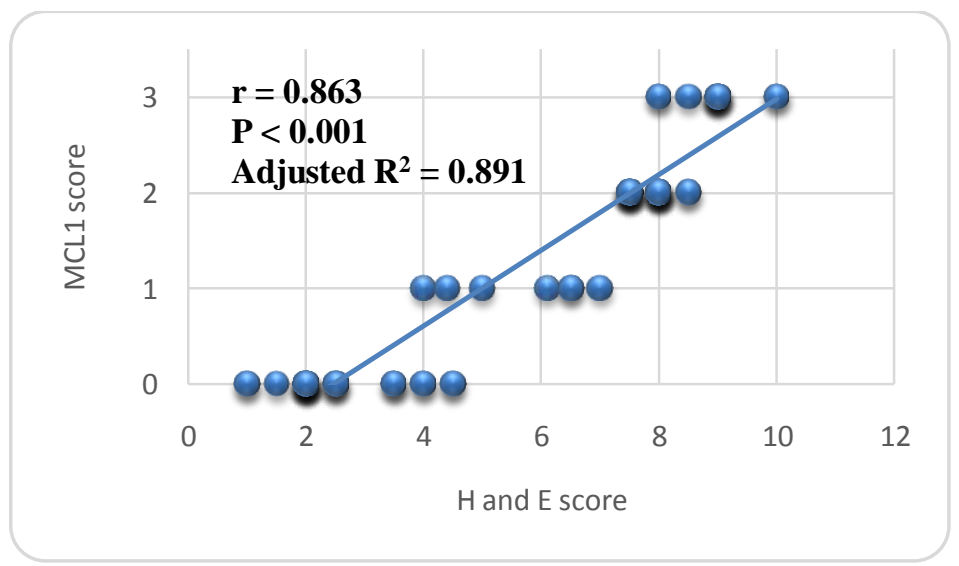

Figure 3:- Correlation between $\mathrm{H}$ and $\mathrm{E}$ scores and MCL1 scores in all patients. 
MCL1 score showed no significant correlation with age, smoking, varicocele, recurrent genitourinary tract infections, exposure to chemical and physical toxins and the presence of congenital anomaly, whereas it showed significant negative correlations with $\mathrm{FSH}, \mathrm{LH}$ and prolactin and significant positive correlation with serum testosterone, table 5 .

Table 5:- Correlation between MCL1 score and other variables.

\begin{tabular}{|c|c|c|}
\hline Variable & r & P \\
\hline Age & -0.006 & $0.966^{*}$ \\
\hline Smoker & 0.057 & $0.634 \dagger$ \\
\hline Varicocele & 0.022 & $0.857 \dagger$ \\
\hline RGUTI & 0.088 & $0.465 \dagger$ \\
\hline Chemical Toxin & -0.030 & $0.803 \dagger$ \\
\hline Physical Toxin & -0.035 & $0.770 \dagger$ \\
\hline Congenital anomaly & 0.171 & $0.154 \dagger$ \\
\hline FSH & -0.548 & $<0.001^{*}$ \\
\hline LH & -0.379 & $0.003^{*}$ \\
\hline Prolactin & -0.429 & $0.001^{*}$ \\
\hline Testosterone & 0.607 & $<0.001^{*}$ \\
\hline
\end{tabular}

*Spearman correlation; †Kindall'sTau_b correlation

Sperms were successfully isolated from 30 patients $(50 \%)$ and the isolation rate was significantly higher in the obstructive azoospermia group than in the non-obstructive azoospermia group, $100 \%$ versus $33.3 \%(\mathrm{P}<0.01)$. Sperm isolation rate was not affected by age of the patient, but it was significantly related to lower FSH, LH and prolactin and higher testosterone level and also it was significantly determined by higher histological and MCL 1 scores, as shown in table 6.

Table 6:- Factors predicting positive sperm isolation.

\begin{tabular}{|l|c|c|c|}
\hline \multicolumn{1}{|c|}{ Characteristic } & Positive $(\mathbf{N}=\mathbf{3 0})$ & Negative $(\mathbf{N}=\mathbf{3 0})$ & P \\
\hline Obstructive /non-obstructive (N) & $15 / 15$ & $0 / 30$ & $<0.001^{*}$ \\
\hline Age $($ mean \pm SD) & $33.40 \pm 8.22$ & $33.23 \pm 6.96$ & $0.933^{* *}$ \\
\hline FSH $($ mean \pm SD) & $9.09 \pm 8.29$ & $13.10 \pm 6.93$ & $0.001^{\dagger}$ \\
\hline LH (mean \pm SD) & $6.49 \pm 3.89$ & $7.52 \pm 2.64$ & $0.028^{\dagger}$ \\
\hline Prolactin $($ mean \pm SD) & $10.03 \pm 4.41$ & $12.69 \pm 3.70$ & $0.014^{* *}$ \\
\hline Testosterone (mean \pm SD) & $12.60 \pm 9.92$ & $3.13 \pm 2.82$ & $0.001 \dagger$ \\
\hline ScoreH\&E (mean \pm SD) & $8.28 \pm 0.73$ & $3.28 \pm 1.68$ & $<0.001 \dagger$ \\
\hline ScoreMCL1 (mean \pm SD) & $2.40 \pm 0.50$ & $0.23 \pm 0.43$ & $<0.001 \dagger$ \\
\hline
\end{tabular}

*Chi-square test; **Independent samples t-test; $\uparrow$ Mann Whitney U test

Successful fertilization was seen in all cases with positive sperm isolation, in other words fertilization rate was $100 \%$ with regard to sperm isolation.

Among those 30 patients with positive fertilization, pregnancy was encountered in 7 patients (23.33\%). It was not statistically associated with type of azoospermia $(\mathrm{P}=0.388)$, also it was not affected by age, serum hormonal level, and histological and MCL 1 scores, table 8.

Table 8:- Factors predicting positive pregnancy outcome.

\begin{tabular}{|l|c|c|c|}
\hline Characteristic & Positive $(\mathbf{N}=\mathbf{7})$ & Negative $(\mathbf{N}=\mathbf{1 6})$ & P \\
\hline Obstructive/non-obstructive N & $5 / 2$ & $10 / 13$ & $0.388^{*}$ \\
\hline Age (mean \pm SD) & $32.86 \pm 6.69$ & $33.57 \pm 8.76$ & $0.825 \dagger$ \\
\hline FSH (mean \pm SD) & $7.46 \pm 5.26$ & $9.58 \pm 9.05$ & $0.750 \dagger$ \\
\hline LH (mean \pm SD) & $6.33 \pm 4.79$ & $6.54 \pm 3.70$ & $0.432 \dagger$ \\
\hline Prolactin (mean \pm SD) & $8.64 \pm 3.81$ & $10.45 \pm 4.57$ & $0.280 \dagger$ \\
\hline Testosterone (mean \pm SD) & $17.01 \pm 10.12$ & $11.26 \pm 9.68$ & $0.091 \dagger$ \\
\hline H\&EScore (mean \pm SD) & $8.64 \pm 0.75$ & $8.17 \pm 0.70$ & $0.109 \dagger$ \\
\hline MCL1Score (mean \pm SD) & $2.71 \pm 0.49$ & $2.30 \pm 0.47$ & $0.057 \dagger$ \\
\hline
\end{tabular}

*Corrected Chi-square test; **Kindall'sTau_b correlation; † Mann Whitney U test 
Histological sections of patients with non-obstructive azoospermia revealed several microscopic patterns: absence of seminiferous epithelium and negative immunoreactivity to MCL-1 (figure 4), Sertoli cells-only with corresponding negative MCL-1 IHC (figure 5), or various stages of incomplete spermatogenesis with a range of week to strong MCL-1 IHC expression (figures 6), whereas obstructive azoospermia showed full spermatogenesis with strong immunoreactivity to Mcl-1 (figure 7).

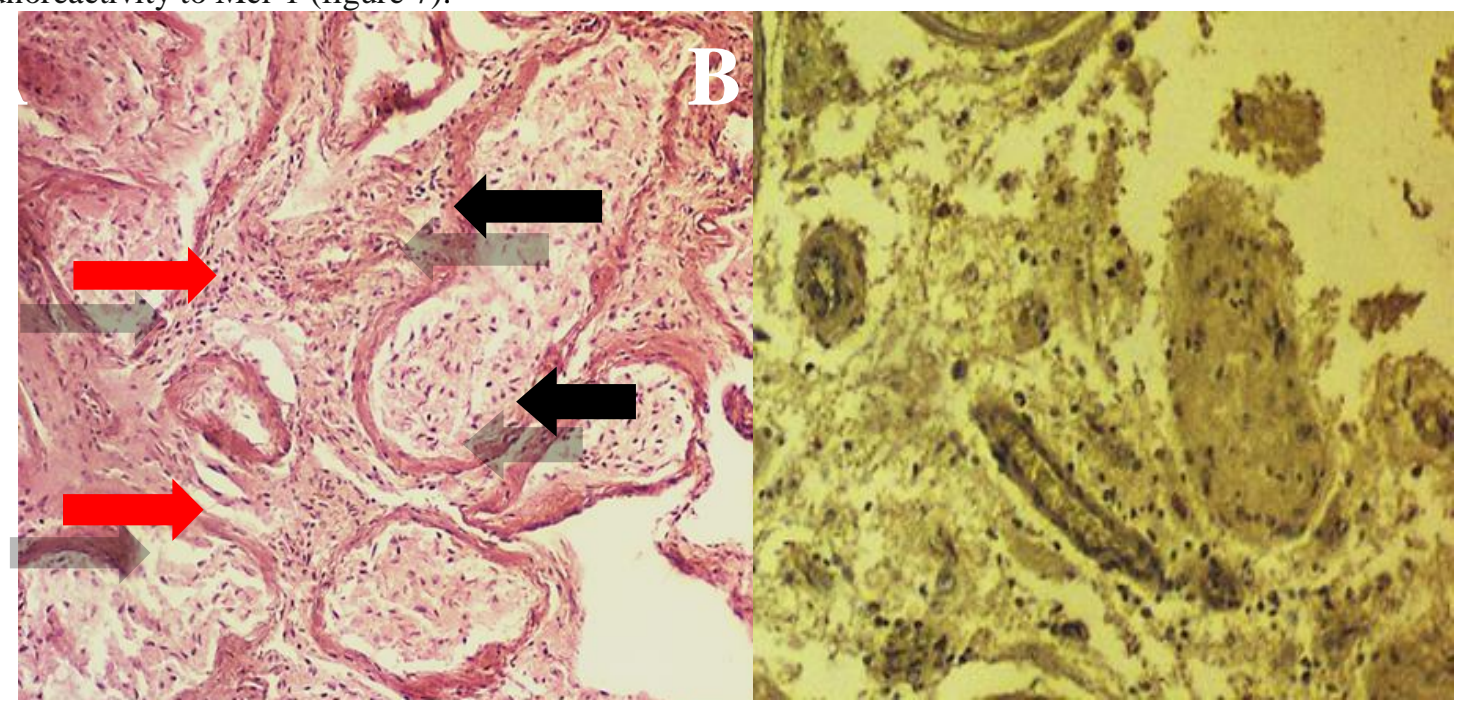

Figure 4:- Seminiferous tubule hyalinization.

A.section of testicular tissue of patient with non-obstructive azoospermia showing Seminiferous tubules surrounded by thickened and hyalinized membranes and absence of seminiferous epithelium ( score 1 according to Modified Johnson scoring system), the tubules are lined with fibroblasts (black arrows), with interstitial fibrosis (red arrows). $\mathrm{H} \& \mathrm{E}, 20 \mathrm{x}$.

B. Section of testicular tissue of the same case showing negative immunohistochemical expression of Mcl-1 (score 0). 400x.

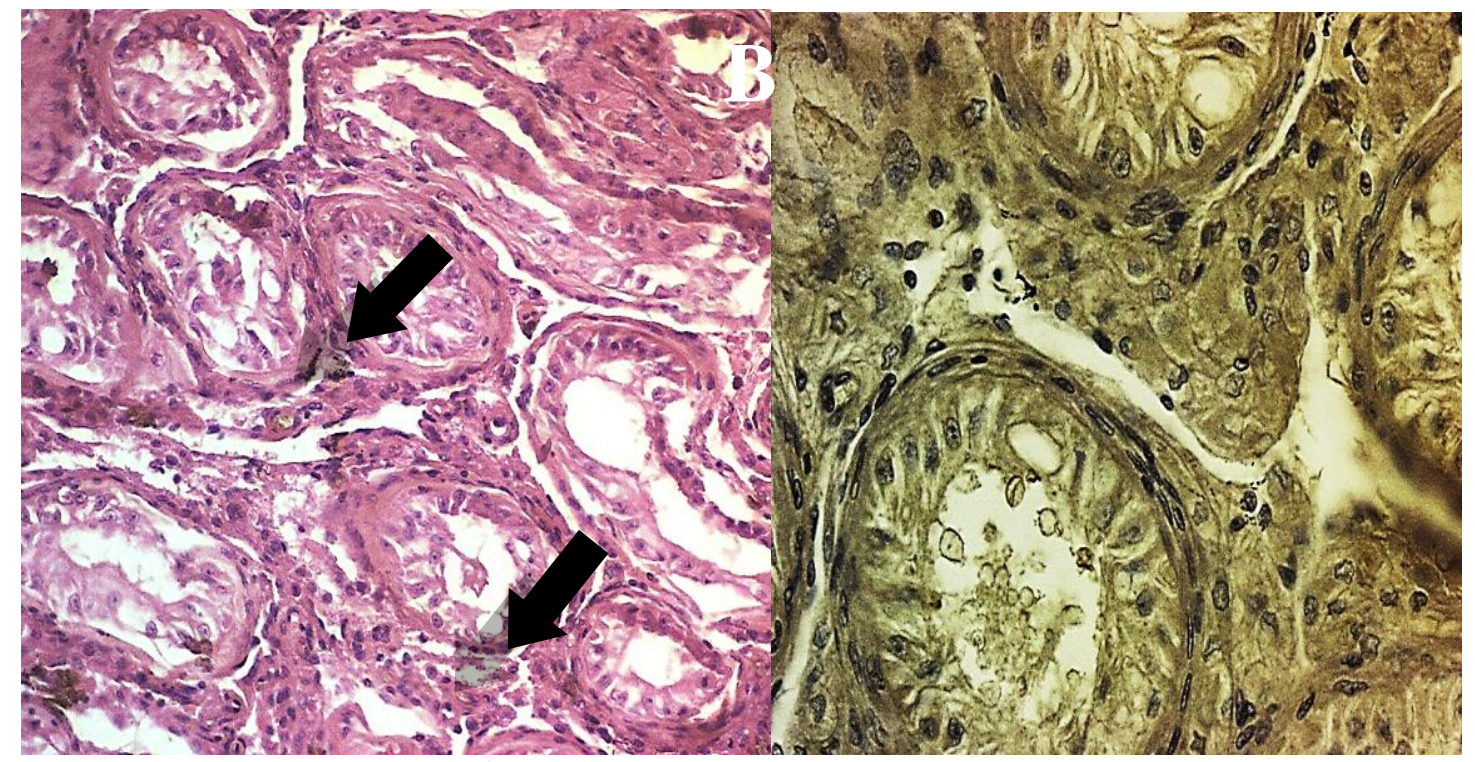

Figure 5:- Sertoli cells-only syndrome.

A. section of testicular tissue of patient with non-obstructive azoospermia showing seminiferous tubules lined by Sertoli cells-only (arrows), with absence of germ cells (score 2). H\&E. 20x.

B. Section of testicular tissue of the same case showing negative immunohistochemical expression of Mcl-1 (score 0). 400x. 


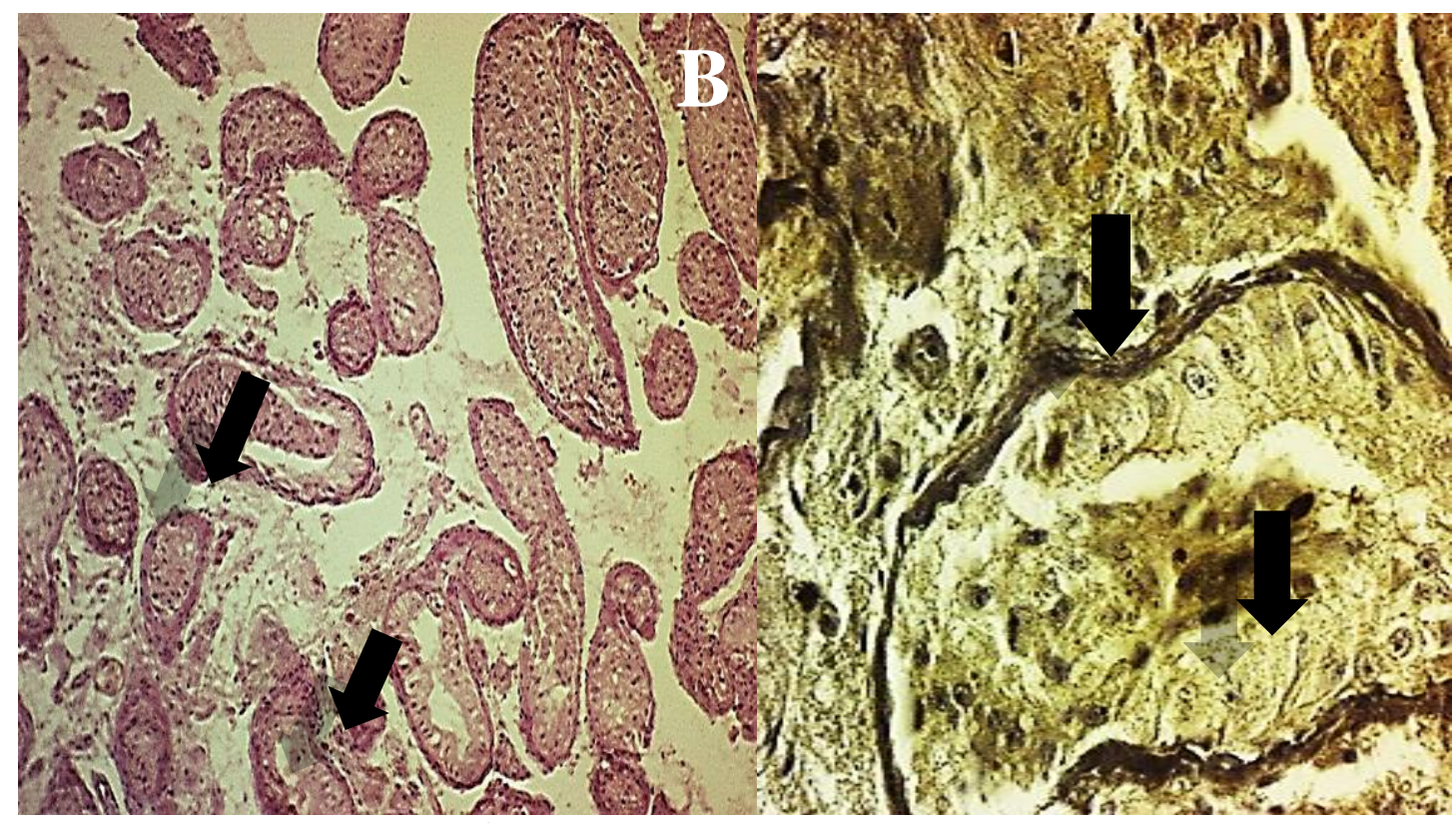

Figure 6:- Germ cell maturation arrest.

A. Section of testicular tissue of patient with non-obstructive azoospermia showing seminiferous tubules lined by sertoli cells and spermatogonia (arrows), (score 3). H\&E. 20x.

B. Section of testicular tissue of the same case showing positive brawn nuclear, cytoplasmic, membranous expression of Mcl-1 of sertoli cells and spermatogonia lining seminiferous tubules (arrows); of weak intensity (score 1+). 400x.

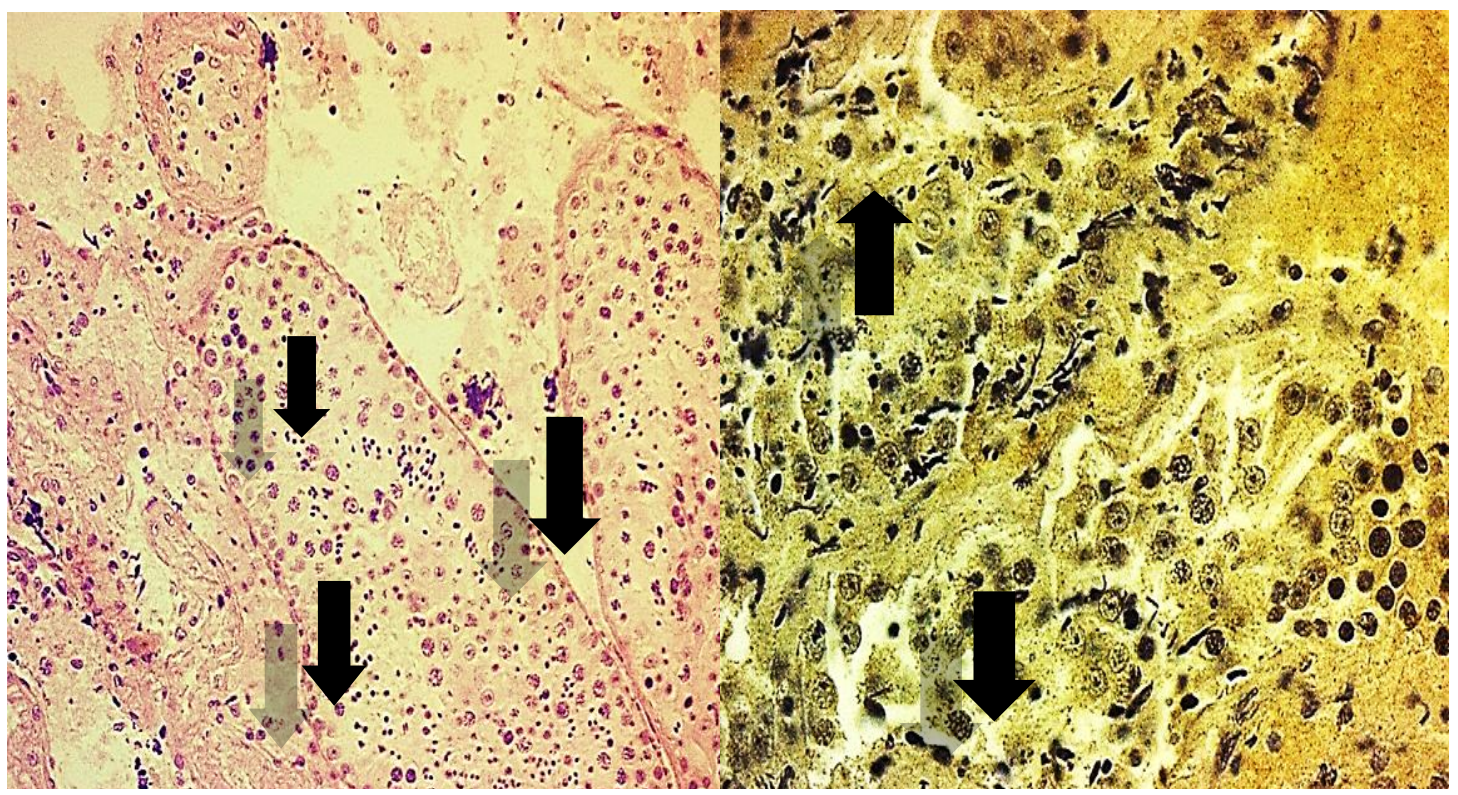

Figure 7:- Normal spermatogenesis.

A. Section of testicular tissue of patient with obstructive azoospermia showingfull spermatogenesis in the seminiferous tubules (arrows), (score 10). H\&E. 20x.

B. Section of testicular tissue of the same case showingpositive brawn nucleus, cytoplasmic, membranous expression of Mcl-1 in all of the cells lining seminiferous tubules (arrows); of strong intensity (score 3+). 400x. 


\section{Discussion:- \\ Histopathology and immunohistochemistry scores}

The results of the current study showed that Mean histological $\mathrm{H}$ and $\mathrm{E}$ score was significantly higher in the obstructive group, $8.67 \pm 0.75$ versus $4.82 \pm 2.60$ ( $\mathrm{P}<0.01$ ). Additionally, mean MCL1 immunohistochemical score was significantly higher in the obstructive group than non-obstructive group, $2.73 \pm 0.46$ versus $0.84 \pm 0.95$ $(\mathrm{P}<0.001)$.

The process of spermatogenesis is based on the equilibrium between proliferation, and apoptosis of germ cells. Throughout various stages of spermatogenesis there should be a role for apoptosis in order to get rid of abnormal spermatogenic cells, and hence maintaining the ratio of germ cell to Sertoli cell with in certain normal range for the propose of lifelong continual spermatogenesis (Razi and Malekinejad, 2015) ${ }^{(\mathbf{6})}$. Nonetheless, when there is excessive apoptosis, there will be severe reduction in sperm production. Apoptosis is regulated by several modulators; some working as anti-apoptotic (Bcl-2, Bcl-x long, Bcl-w, Mcl-1, A1/Bfl1, and $\mathrm{Nr} 13$ ) while others enhance apoptosis (Bax, Bcl-x short, Bak, and Bok) (Hardwick and Soane, 2013) ${ }^{(7)}$.

MCL-1 is unique among pro-survival BCL-2 family members in that it is essential for embryonic development and for the survival of multiple cell lineages in the adult including: lymphocytes, hematopoietic stem cells, neutrophils, and neurons. Moreover, $M C L-1$ is frequently amplified in human cancers and associated with chemotherapeutic resistance and relapse (Kafaraet al., 2015) ${ }^{(\mathbf{8})}$.

The significantly lower MCL-1 score in non-obstructive azoospermia type, recorded in the current study, implies that apoptosis is higher in those group and may play a significant role in the pathogenesis of azoospermia. This finding opens the discussion toward the benefit of using some anti-MCL-1 strategy to reduce apoptosis in those patients and subsequently may improve their spermatogenesis. On the other hand the high MCL-1 score, in the present study, was correlated with positive sperm retrieval; hence it can be used as an indicator for success or failure of assisted reproduction in patients with infertility. Hegazyet al. in $2015^{(9)}$ investigated the immunohistochemical expression in testicular biopsies obtained from patients with azoospermia and he found out that a strong positive immunoreaction in Leydig cells was observed among all investigated specimens; a moderate reaction was detected in spermatocytes and spermatozoa in cases of normal spermatogenesis and hypospermatogenesis, but a negative reaction was detected in cases of maturation arrest and germ cell aplasia, and concluded that apoptosis was found to be associated with decreased rate of spermatogenesis and that high apoptosis rates may result in azoospermia.

\section{Sperm isolation rate and fertilization rate:-}

The present study showed that Sperms were successfully isolated from 30 patients (50\%) and that the isolation rate was significantly higher in the obstructive azoospermia group than in the non-obstructive azoospermia group, 100\% versus $33.3 \%(\mathrm{P}<0.01)$; these results were comparable to the finding of other studies in which sperm retrieval rate was higher in obstructive azoospermia in comparison with non-obstructive type (61\%) (Moeinet al., 2015) ${ }^{(\mathbf{1 0})}$. It was also, similar to the present study finding, stated by some authors that testicular sperm recovery from azoospermic males with all diagnoses was high (70 to 100\%) except non-obstructive azoospermia (31\%) (Omurtaget al., 2013) ${ }^{(\mathbf{1 1})}$. In the current study, sperm isolation rate was not affected by age of the patient, but it was significantly related to lower FSH, LH and prolactin and higher testosterone level and also it was significantly determined by higher histological and MCL 1 scores. We agreed with Kalsiet al., 2015 ${ }^{(\mathbf{1 2})}$ that age of the patient has no significant effect on sperm retrieval rate; however we disagree with him in that FSH level had no significant impact on rate of sperm retrieval. In accordance with the present study findings, it was found that sperm isolation was significantly affected by FSH, LH and testosterone level (Modarresiet al., 2015) ${ }^{(\mathbf{1 3 )}}$.

\section{Pregnancy rate:-}

Several studies showed that there is no statistically significant difference in clinical pregnancy rates between the two groups (Merchant et al., 2011) ${ }^{(\mathbf{1 4})}$ and this result solidify the finding of the present study which also found no significant difference in clinical pregnancy rate between obstructive and non-obstructive azoospermia rate. In accordance with the result of the present study it was found that there was no differences were noted in clinical pregnancy rate between obstructive azoospermia and non-obstructive azoospermia groups (Omurtaget al., 2013) ${ }^{(\mathbf{1 1 1}}$.In contradiction to the finding of the current study, rate of fertilization was significantly lower with nonobstructive azoospermia (Omurtaget al., 2013) ${ }^{(\mathbf{( 1 1})}$. It has also been recorded that fertilization and clinical pregnancy rates was lower in non-obstructive azoospermia (Tehraninejadet al., 2012) ${ }^{(\mathbf{1 5})}$; However a meta-analysis of surgical sperm retrieved in azoospermic patients concluded that sperm origin does not affect assisted fertilization cycle 
outcome (Kalsiet al., 2011) ${ }^{(\mathbf{1 6})}$. Another similar result to our finding has been registered by (Tsaiet al., 2015) ${ }^{(\mathbf{1 7 )}}$ who found no significant difference in clinical pregnancy rate between the two groups.

\section{References:-}

1. Cocuzza M, Alvarenga C, Pagani R. The epidemiology and etiology of azoospermia. Clinics. 2013; 68 (1):1526.

2. Foghi K, Novin MG, Jabbari ZM. et al. Immuno-histochemical localization of endothelial nitric oxide synthase in testicular cells of men with non-obstructive azoospermia. Iranian Journal of Reproductive Medicine. 2011; 9(4):277-80.

3. Kumar R. Medical management of non-obstructive azoospermia. Clinics. 2013; 68(1): 75-79.

4. Almeida C, Correia S, Rocha E, et al. Caspase signaling pathways in human spermatogenesis. Journal of Assisted Reproduction and Genetics. 2013; 30(4):487-95.

5. Morciano G, Giorgi C, Balestra D, et al. Mcl-1 involvement in mitochondrial dynamics is associated with apoptotic cell death. Newmeyer DD, ed. Molecular Biology of the Cell. 2016; 27(1):20-34.

6. Razi, M, Malekinejad H.Varicocele-Induced Infertility in Animal Models. International Journal of Fertility \& Sterility. 2015; 9(2), 141-49.

7. Hardwick JM, Soane L.Multiple Functions of BCL-2 Family Proteins. Cold Spring Harbor Perspectives in Biology. 2013; 5(2): 10.

8. Kafara P, Icard P, Guillamin M. et al. Lipoic acid decreases Mcl-1, Bcl- $\mathrm{x}_{\mathrm{L}}$ and up regulates Bim on ovarian carcinoma cells leading to cell death. Journal of Ovarian Research. 2015; 8: 36.

9. Hegazy R, Hegazy A, Ammar M. et al.Immunohistochemical measurement and expression of Mcl-1 in infertile testes. Front Med. 2015; 9 (3):361-67.

10. Moein MR, Moein MR, Ghasemzadeh J. Evaluation of sperm retrieval rate with bilateral testicular sperm extraction in infertile patients with azoospermia. Iranian Journal of Reproductive Medicine. 2015; 13(11), 71114.

11. Omurtag K, Cooper A, Bullock A. et al. Sperm Recovery and IVF after Testicular Sperm Extraction (TESE): Effect of Male Diagnosis and Use of Off-Site Surgical Centers on Sperm Recovery and IVF. PLoS ONE. 2013; 8(7): e69838.

12. Kalsi JS, Shah P, Thum Y. et al. Salvage micro-dissection testicular sperm extraction; outcome in men with non-obstructive azoospermia with previous failed sperm retrievals. BJU Int. 2015; 116: 460-65.

13. Modarresi T, Hosseinifar H, Hampa, AD. et al. Predictive Factors of Successful Microdissection Testicular Sperm Extraction in Patients with Presumed Sertoli Cell-Only Syndrome. International Journal of Fertility and Sterility. 2015; 9(1): 107-12.

14. Merchant R, Gandhi G, Allahbadia GN. In vitro fertilization/intracytoplasmic sperm injection for male infertility. Indian J Urol. 2011;27(1): 121-32.

15. Tehraninejad EST, Pourmatroud E, Gilani MAS. et al. A. Comparison of Intracytoplasmic Sperm Injection Outcomes between Oligozoospermic, Obstructive Azoospermic and Non-Obstructive Azoospermic Patients. International Journal of Fertility and Sterility. 2012; 6(1): 13-18.

16. Kalsi J, Thum MY, Muneer A. et al. Analysis of the outcome of intracytoplasmic sperm injection using fresh or frozen sperm. BJU Int. 2011; 107:1124-28.

17. Tsai Y, Huang F, Lin P. et al. Clinical outcomes and development of children born to couples with obstructive and non-obstructive azoospermia undergoing testicular sperm extraction-intracytoplasmic sperm injection: A comparative study. Taiwanese Journal of Obstetrics and Gynecology. 2015; 54 (2): 155 - 59. 